\title{
Endogenous Market Structures and the Gains from Foreign Direct Investment
}

\author{
Roberto A. De Santis \\ European Central Bank \\ D-60311 Frankfurt am Main, Germany \\ roberto.de_santis@ecb.int \\ Frank Stähler \\ Department of Economics \\ University of Kiel \\ Wilhelm-Seelig-Platz 1 \\ D-24098 Kiel, Germany \\ fstaehler@econ-theory.uni-kiel.de
}

First draft: November 1999

This draft: November 2001

\footnotetext{
${ }^{1}$ We would like to thank Jonathan Eaton, Horst Raff, Gerald Willmann, Jim Markusen, Antony Venables and two anonymous referees for helpful comments or discussions. This paper has been written while the authors were at the Kiel Institute of World Economics. The views expressed in this study are those of the authors and do not necessarily reflect those of the European Central Bank. All errors are authors responsability.
} 


\begin{abstract}
This paper discusses the gains from liberalizing foreign direct investment (FDI) in a two country setting with endogenous market structures. Two different scenarios are investigated. In the first scenario, headquarters are run in the domestic country only and the FDI regime is compared to the intersectoral trade case. If multinational and national firms coexist, market concentration occurs and FDI is welfare improving for the foreign country, but welfare declining for the domestic country. In the second scenario, headquarters are run in both countries and the FDI regime is compared to the intraindustry trade case. This regime switch leads to mutual welfare gains, irrespective of market structure effects.
\end{abstract}

JEL-Classification: F12, F15.

Keywords: Foreign direct investment, Multinational enterprises, Imperfect competition, Welfare. 


\section{Introduction}

The stylized facts of recent years suggest that economic integration among countries does not only take place via trade but also via FDI. The latter has been growing at a high rate, even though trade barriers have fallen extensively. In fact, the World Investment Report of the United Nations (2000) gives a projection of the sales of foreign affiliates of 13,6 trillions of US Dollars for the year 1999; whereas, in the same period, exports of goods and non-factor services amounted to 6,9 trillions of US Dollars. In other words, the value of aggregate production of multinational firms in the host country nowadays outweighs aggregate exports.

These new facts have motivated the study of the theory of the multinational firm, which started in the middle eighties and was developed in the nineties. The literature distinguishes between horizontal FDI (Markusen, 1984; Horstmann and Markusen, 1992; Brainard, 1993; Markusen and Venables 1998, 2000), which is undertaken to place production closer to foreign markets; and vertical FDI (Helpman, 1984; Helpman and Krugman, 1985), which is undertaken to exploit lower production costs in order to serve both the domestic and the foreign markets. Thus, FDI can substitute for trade, when production in the host country replaces exports (horizontal FDI); but it can be complementary to trade, when a part of the production in the host country is shipped back to the home country (vertical FDI).

In this study, we focus our analysis on the welfare effect of FDI, when FDI and exports are perfect substitutes. ${ }^{1}$ It must be stressed that, although the classical and the 'new trade' theory have discussed welfare effects in detail, the welfare impact of FDI has received little attention. The simultaneous

\footnotetext{
${ }^{1}$ The underlying assumption is that FDI is undertaken by multinational firms to be closer to the foreign market. This argument is often used to explain the large intra-flow of FDI among developed countries (see, for example, Markusen and Venables, 1998). Also Markusen (1998), in summarizing the results of the empirical literature, points out that multinational firms engage their activities with countries that are more similar in size, relative endowments and per capita incomes, and that most FDI seems to be horizontal. For recent contributions which discuss the econometric evidence in support of an horizontal relationship between trade and FDI, see Brainard (1997), Blonigen (2001), Markusen and Maskus (2001).
} 
treatment of trade and FDI has already been discussed in the literature, in particular in two papers, one by Horstmann and Markusen (1992) and the other by Markusen and Venables (1998). Horstmann and Markusen (1992) deal analytically with the different type of firms, that is national and multinational firms. However, they do not allow for market entry. More recent contributions by Markusen and Venables (1998, 2000) can explain simultaneously and endogenously the type and the number of active firms in each country. However, given the complexity of these models, they are not able to study analytically the effects of multinationals. These models are solved by means of numerical simulations.

The aim of this study is to explain analytically both the type and the number of firms, and the impact on welfare in the home and the host country of a regime switch from trade to FDI. The model is similar to the setting employed in Horstmann and Markusen (1992), but with free entry/exit, as assumed in Markusen and Venables (1998). Due to the free entry/exit assumption, the welfare analysis can be done by comparing the equilibrium prices of two alternative regimes. In the first instance, FDI is banned, and the foreign market is served with exports (i.e. trade regime). Then, FDI is liberalized, and firms may choose between exporting or locating production in the host country (i.e. FDI regime). This regime switch has an impact on market structure and welfare, whose analysis is the purpose of this paper.

Following the eclectic paradigm of Dunning (1977), multinational firms are induced to invest abroad if, in addition to location advantages (that is lower production costs), they have ownership advantages and internalization advantages (that is no interest in selling licenses to foreign firms). Thus, we assume that the oligopolistic industry needs specific skills to be able to run the headquarters of a large-scale firm. We measure this requirement by the labor input. Since the labor input needed to set up the headquarters of an oligopolistic firm may differ substantially among countries, we explore the economic implications of FDI by using as a reference point two alternative scenarios. In the first scenario, the specific skills to run the headquarters are concentrated in one country so that the oligopolistic industry exists only in this country (say the domestic country). In the second scenario, the head- 
Table 1: Overview of the model

\begin{tabular}{|c|cc|}
\hline & \multicolumn{2}{|c|}{ Headquarters are run ... } \\
& in the domestic country only & in both countries \\
\hline FDI banned & Intersecoral trade & Intraindustry trade \\
FDI allowed & FDI vs intersectoral trade & FDI vs intraindustry trade \\
\hline
\end{tabular}

quarters are run in both countries so that the oligopolistic industry is present in both countries. We will then discuss the effects of lifting an FDI ban in both scenarios, given that the parameter values make FDI profitable. So FDI is treated as a policy shift and the distribution of skills to run headquarters is considered exogenous; whereas the number of active firms, the location of plants and, hence, the type of active firms are determined endogenously in the context of these two models. Table 1 sketches the two scenarios under investigation.

Accordingly, the plan of the paper is as follows. Section 2 presents the framework of the model. Section 3 explores the effects on market structure and welfare of FDI liberalization, when headquarters are run in the domestic country only. Section 4 discusses the implications of FDI liberalization, when headquarters are run in both countries. Section 5 concludes.

If headquarters are run in the domestic country only and FDI is profitable, we find that two alternative equilibria are possible: (i) a mixed equilibrium, where both national and multinational firms coexist; (ii) an equilibrium, where only multinational firms exist. In the mixed equilibrium, the foreign country gains but the domestic country loses in terms of welfare. In an equilibrium with only multinational firms the impact on the welfare of the domestic country depends upon parameter values. We also show that market concentration occurs in the mixed equilibrium, whereas the impact on market structure depends upon parameter values in the equilibrium with only multinational firms. If the headquarters are run in both countries, only multinational firms will be active in the market once FDI is liberalized and profitable. We show that FDI compared to intraindustry trade leads to mutual welfare gains, irrespective of the impact on market structure, which 
depends upon parameter values.

\section{The model}

The model used in this paper is similar to the model employed by Horstmann and Markusen (1992). The world consists of two countries, a domestic country $d$ and a foreign country $f$. Each country is endowed with a certain amount of a productive factor, such as labor $L$. In both countries, a homogeneous good $Y$ is produced using only the labor input, so that $L^{Y}=Y$, where the superscript denotes the sector in which labor is used. The price of $Y$ or the return on $L$ is the numeraire of the model. Exporting $Y$ is assumed to incur no trade costs. In order to keep the structure of the model simple, the consumer behavior in each country is determined by the linear quadratic utility function $U_{i}\left(X_{i}, Y_{i}\right)=\alpha X_{i}-0.5 \beta X_{i}^{2}+Y_{i}$. Given the aggregate budget resource constraint $L_{i}+\sum \pi_{i}=p_{i} X_{i}+Y_{i}, i \in\{d, f\}$, where $\sum \pi_{i}$ denotes the aggregate profits of the oligopolistic industry and $p_{i}$ the price of $X_{i}$ in terms of the numeraire, maximization of $U_{i}$ subject to the resource constraint yields the inverse income inelastic demand function

$$
p_{i}=\alpha-\beta X_{i}, i \in\{d, f\}
$$

The oligopolistic industry is characterized by imperfect competition and Cournot behavior. Each firm produces one good, which is traded within the home market and exported or produced abroad. Exports and FDI are assumed to be perfect substitutes, which implies that we focus our analysis upon horizontal FDI. Firms' production decisions depend on the fixed costs, the marginal cost $c$ and the trade costs $t$ with $\alpha-c-t>0$. Fixed costs, $c$ and $t$ are measured in units of labor required. Markets are considered to be segmented so that each firm is able to regard each country as a separate market. Thus, each firm maximizes its profit function with respect to both the sales in the foreign market and the production for the domestic market, and chooses the profit-maximizing quantity for each country separately. However, we show that the same results hold also in the hypothesis that markets were integrated. 
The profits of a national firm are

$$
\pi^{n}=\left(p_{d}-c\right) x_{d}^{n}+\left[p_{f}-(c+t)\right] x_{f}^{n}-F_{d},
$$

where $x_{d}^{n}$ and $x_{f}^{n}$ represent the production of a national firm for the domestic and the foreign market, respectively; $F_{d}$ is the fixed set-up costs for home and export production. These fixed costs comprise the investment costs for headquarters and one production plant in the domestic country. The superscript $n$ denotes the case of national firms.

The profits of a multinational firm are

$$
\pi^{m}=\left(p_{d}-c\right) x_{d}^{m}+\left(p_{f}-c\right) x_{f}^{m}-F_{d}-F_{f},
$$

where $x_{d}^{m}$ and $x_{f}^{m}$ represent the production of a multinational firm for the domestic and the foreign market, respectively; and $F_{f}$ the fixed costs needed to start the production process abroad (that is, the plant-specific fixed costs). The superscript $m$ denotes the case of multinational firms. In summary, multinational firms are able to produce for the foreign market without incurring trade costs, but they have to carry the additional fixed cost burden needed to set up the production process abroad. We assume that $F_{f}<F_{d}$ and that a firm cannot set up a plant abroad without first setting up one at home.

In Section 3, we assume that headquarters are run in the domestic country only. More formally, we assume that $F_{d}$ is prohibitively high in the foreign country. Then, the trade regime is characterized by intersectoral trade as firms cannot be established in the foreign country. Due to this asymmetry in the labor input requirement to run headquarters and a production plant, the oligopolistic industry can exist only in the domestic country. If FDI is banned, the equilibrium in the goods markets is given by $X_{d}=N x_{d}^{n}$ and $X_{f}=N x_{f}^{n}$, where $N$ denotes the total number of national firms. In equilibrium, each firm maximizes profits (2) given the equilibrium output of its rivals, and entry occurs until the excess profits of the marginal firm are driven to zero. Since firms are symmetric, all firms earn zero profits in equilibrium. This condition allows us to determine the equilibrium number of national firms, 
the equilibrium individual output levels and the equilibrium prices in both countries:

$$
\begin{gathered}
N^{*}=\sqrt{\frac{(\alpha-c)^{2}+(\alpha-c-t)^{2}}{\beta F_{d}}-1,} \\
x_{d}^{*}=\frac{\alpha-c}{\beta\left(N^{*}+1\right)}=(\alpha-c) \sqrt{\frac{F_{d}}{\beta\left[(\alpha-c)^{2}+(\alpha-c-t)^{2}\right]}}, \\
x_{f}^{*}=\frac{\alpha-c-t}{\beta\left(N^{*}+1\right)}=(\alpha-c-t) \sqrt{\frac{F_{d}}{\beta\left[(\alpha-c)^{2}+(\alpha-c-t)^{2}\right]}}, \\
p_{d}^{*}=\frac{\alpha+c N^{*}}{N^{*}+1}=c+(\alpha-c) \sqrt{\frac{\beta F_{d}}{(\alpha-c)^{2}+(\alpha-c-t)^{2}}}, \\
p_{f}^{*}=\frac{\beta F_{d}}{N^{*}+1}=c+t+(\alpha-c-t) \sqrt{\frac{(\alpha-c)^{2}+(\alpha-c-t)^{2}}{(\alpha+1)}} .
\end{gathered}
$$

Note that price differences are sustainable in integrated markets only if they do not exceed trade costs (see, for example, Wong, 1995, 305-319). Since $p_{f}^{*}-p_{d}^{*}=N^{*} t /\left(N^{*}+1\right)<t$, (4)-(6) give also the equilibrium values in the hypthesis that markets were integrated.

In Section 3, we investigate the impact on market structure and welfare, when the trade regime represented by (4)-(6) is replaced by a regime where FDI is liberalized, under the hypothesis that the parameters of the model make FDI profitable and

$$
F_{d}<\frac{(\alpha-c)^{2}+(\alpha-c-t)^{2}}{\beta}
$$

Condition (7) is required for a firm wanting to be active in the intersectoral trade case (that is, $N^{*}>0$ ).

In Section 4, we assume that headquarters are run in both countries. If FDI is banned, the trade regime is characterized by intraindustry trade, and the model coincides with the reciprocal dumping model of Brander (1981), and Brander and Krugman (1983). By symmetry we need to consider only 
the domestic country. The equilibrium in the commodity market is then $X_{d}=X_{f}=0.5 N\left(x_{d}+x_{f}\right)$, where $N$ denotes the total number of national firms active in both countries. The equilibrium values for the number of firms, individual output levels and prices are:

$$
\begin{gathered}
\tilde{N}=\frac{(\alpha-c)+(\alpha-c-t)}{\sqrt{2 \beta F_{d}-t^{2}}-1,} \\
\tilde{x}_{d}=\frac{\alpha-c+0.5 \tilde{N} t}{\beta(\tilde{N}+1)}=\frac{\sqrt{2 \beta F_{d}-t^{2}}+t}{2 \beta}, \\
\tilde{x}_{f}=\frac{\alpha-c-(0.5 \tilde{N}+1) t}{\beta(\tilde{N}+1)}=\frac{\sqrt{2 \beta F_{d}-t^{2}}-t}{2 \beta}, \\
\tilde{p}=\frac{\alpha+\tilde{N} c+0.5 \tilde{N} t}{\tilde{N}+1}=c+\frac{t+\sqrt{2 \beta F_{d}-t^{2}}}{2} .
\end{gathered}
$$

Since prices in both countries coincide, (8)-(10) give also the equilibrium values in integrated markets. ${ }^{2}$ Note that intraindustry trade occurs (that is, $\tilde{x}_{f}>0$ ) if, and only if, $t^{2}<\beta F_{d}$. This condition is needed to ensure that there are not too many local firms making exports not worthwhile. In addition, the market exists (that is, $\tilde{N}>0$ ) if, and only if, $F_{d}$ is lower than $\left[(\alpha-c)^{2}+(\alpha-c-t)^{2}\right] / \beta$. Therefore, Section 4 investigates the impact on market structure and welfare, when the trade regime represented by (8)-(10) is replaced by the FDI regime, under the hypothesis that the parameters of the model make FDI profitable and

$$
\frac{t^{2}}{\beta}<F_{d}<\frac{(\alpha-c)^{2}+(\alpha-c-t)^{2}}{\beta}
$$

\section{$3 \quad$ FDI versus intersectoral trade}

This section assumes that the headquarters of the oligopolistic industry are run in the domestic country only, so that national firms serve the foreign

\footnotetext{
${ }^{2}$ Since also the intra-FDI regime yields symmetric prices, the results in Section 4 do hold for both integrated and segmented markets.
} 
country via exports and multinational firms via FDI. The equilibrium number of national and multinational firms can be determined by solving the optimizing behavior of firms under the zero profit conditions. Express $M$ as the number of multinational firms. In this case, aggregate outputs are determined by $X_{d}=N x_{d}^{n}+M x_{d}^{m}$ and $X_{f}=N x_{f}^{n}+M x_{f}^{m}$. The optimizing solution under the zero profit conditions (2) and (3) results in two non-linear equations in $N$ and $M$,

$$
\begin{gathered}
f(N, M):=\frac{(\alpha-c)^{2}}{\beta(N+M+1)^{2}}+\frac{[\alpha-c-(M+1) t]^{2}}{\beta(N+M+1)^{2}}-F_{d}=0, \\
g(N, M):=\frac{(\alpha-c)^{2}}{\beta(N+M+1)^{2}}+\frac{(\alpha-c+N t)^{2}}{\beta(N+M+1)^{2}}-\left(F_{d}+F_{f}\right)=0,
\end{gathered}
$$

where $f$ denotes the zero profit condition for national firms, and $g$ denotes the zero profit condition for multinational firms.

In order to examine the impact on market structure, the definition of two critical values of $F_{f}$ will prove useful. Let $\overline{F_{f}}$ denote the minimum fixed costs which yield $M=0$, and let $F_{f}$ denote the maximum fixed costs which yield $N=0 . \overline{F_{f}}$ (and $\left.N\right)$ is determined by setting $f(N, 0)=g(N, 0)=0$, whereas $\underline{F_{f}}($ and $M)$ is determined by setting $f(0, M)=g(0, M)=0$ :

$$
\begin{gathered}
\overline{F_{f}}=\frac{t}{\beta}\left(t+2(\alpha-c-t) \sqrt{\frac{\beta F_{d}}{(\alpha-c)^{2}+(\alpha-c-t)^{2}}}\right), \\
\underline{F_{f}}=\frac{t}{\beta} \sqrt{2 \beta F_{d}-t^{2}} .
\end{gathered}
$$

By using (14) and (15), we can demonstrate Proposition 1.

Proposition 1: A unique equilibrium exists in the case of intersectoral trade and potential FDI. If $\left.F_{f} \in\right] \overline{F_{f}}, \infty[$, only national firms are active. If $F_{f} \in\left[0, \underline{F_{f}}\left[\right.\right.$, only multinational firms are active. If $F_{f} \in\left[\underline{F_{f}}, \overline{F_{f}}\right]$, national and multinational firms coexist. 
Proof: National firms will emerge if $F_{f}>\overline{F_{f}}$, because $\overline{F_{f}}$ is determined from (12) and (13) by setting $M$ equal to zero. Any higher $F_{f}$ would only deepen the cost disadvantage of multinational firms. By contrast, multinational firms will emerge if $F_{f}<F_{f}$, because $F_{f}$ is determined from (12) and (13) by setting $N$ equal to zero. Any lower $\overline{F_{f}}$ would only deepen the profitability of multinational firms. If, however, $\overline{F_{f}}>\underline{F_{f}}$ in the relevant range of $t$ and $F_{d}$, then a range of $F_{f}$ exists in which a mixed equilibrium occurs. For the mixed equilibrium proof, define $\Delta:=(\beta / t)\left(\overline{F_{f}}-\underline{F_{f}}\right)$. If $\Delta>0$, a mixed equilibrium may exist. First, let us explore the $\Delta$-function in the relevant range. We observe that $\Delta=0$, if $F_{d}=\left[(\alpha-c)^{2}+(\alpha-c-t)^{2}\right] / \beta$. However, this level of fixed costs implies that the market does not exist, because even a single firm is not able to recoup its fixed costs (see condition (7)). Hence, the relevant fixed costs must be below this level. If $\Delta$ decreases with $F_{d}$ in the relevant range, we have shown that $\Delta$ is positive, since it reaches zero at the border where the market does not exist under the intersectoral trade case. Differentiation yields

$$
\frac{\partial \Delta}{\partial F_{d}}=\beta\left(\frac{\alpha-c-t}{\sqrt{\beta F_{d}\left[(\alpha-c)^{2}+(\alpha-c-t)^{2}\right]}}-\frac{1}{\sqrt{2 \beta F_{d}-t^{2}}}\right) .
$$

This term is negative if, and only if, $t>-\beta F_{d}[2(\alpha-c)-t] /[\alpha-c-t]^{2}$, which is always fulfilled. Hence, a mixed equilibrium may exist.

With regard to the uniqueness of this equilibrium, the appendix proves that the Jacobian of (12) and (13) is unambiguously positive: $|J|=$ $\eta^{2} /[2 \beta(\alpha-c) t]^{2}>0$, where $\eta:=4 \beta F_{d} t^{2}-\left(\beta F_{f}-t^{2}\right)^{2}{ }^{3}$ It shows that this property holds also for the corner solutions of the mixed equilibrium, where $M=0$ or $N=0$. Hence, this property proves that the equilibrium is unique. The proof can be given by contradiction. Suppose that multiple mixed equilibria exist. In this case both the $f$ - and the $g$-function should intersect at least twice. However, both the $f$ - and the $g$-function are twice continuously differentiable and have a negative slope (see appendix). If they intersect twice, the second intersection should imply a Jacobian with an opposite sign. How-

\footnotetext{
${ }^{3}$ Note that $\eta$ is unambiguously positive in the case of a mixed equilibrium. Since $F_{f}$ should be less than $\overline{F_{f}}, \eta$ must be larger than $4 \beta F_{d} t^{2}(\alpha-c)^{2} /\left[(\alpha-c)^{2}+(\alpha-c-t)^{2}\right]>0$.
} 
ever, the Jacobian is always positive. Hence, any mixed equilibrium must be unique.

Regarding the market structure in the mixed equilibrium, (12) and (13) can be solved explicitly for the equilibrium values of $N$ and $M$ :

$$
\begin{gathered}
N^{e}=\frac{\alpha-c}{t}\left(\frac{\beta F_{f}+t^{2}}{\sqrt{\eta}}-1\right), \\
M^{e}=\frac{\alpha-c}{t}\left(1-\frac{\beta F_{f}-t^{2}}{\sqrt{\eta}}\right)-1 .
\end{gathered}
$$

The superscript $e$ denotes the equilibrium values in the case of coexistence of national and multinational firms. The four f.o.c.'s and the two inverse demand functions (1) determine the equilibrium outputs and prices for both the domestic and the foreign market:

$$
\begin{array}{r}
p_{d}^{e}=\frac{\alpha+c\left(N^{e}+M^{e}\right)}{N^{e}+M^{e}+1}=c+\frac{\sqrt{\eta}}{2 t}, \\
p_{f}^{e}=\frac{\alpha+(c+t) N^{e}+c M^{e}}{N^{e}+M^{e}+1}=c+\frac{\beta F_{f}+t^{2}}{2 t}, \\
x_{d}^{n e}=x_{d}^{m e}=\frac{\alpha-c}{\beta\left(N^{e}+M^{e}+1\right)}=\frac{\sqrt{\eta}}{2 \beta t}, \\
x_{f}^{n e}=\frac{\alpha-c-t\left(M^{e}+1\right)}{\beta\left(N^{e}+M^{e}+1\right)}=\frac{\beta F_{f}-t^{2}}{2 \beta t}, \\
x_{f}^{m e}=\frac{\alpha-c+t N^{e}}{\beta\left(N^{e}+M^{e}+1\right)}=\frac{\beta F_{f}+t^{2}}{2 \beta t} .
\end{array}
$$

Note that the size of the multinational firm is larger than the size of the national firm $\left(x_{f}^{m e}-x_{f}^{n e}=t / \beta\right)$, because the former has to carry larger aggregate fixed costs. ${ }^{4}$ Note that $p_{d}^{e}$ and $p_{f}^{e}$ are also the equilibrium prices in integrated markets, as $p_{f}^{e}-p_{d}^{e}=N^{e} t /\left(N^{e}+M^{e}+1\right)<t$.

\footnotetext{
${ }^{4}$ At first glance, one might argue that, if $\beta F_{f}<t^{2}$, the mixed equilibrium would be characterized by national firms serving the domestic market only. However, if exports vanish, it can be easily shown that national firms are not longer profitable and they would all exit the market. In fact, this hypothetical equilibrium would violate the plausible assumption that $F_{f}<F_{d}$. The proof is available upon request.
} 
Since $|J|>0$, the slope of $f$ is steeper than that of $g$ at the equilibrium point. Hence, (17) and (18) intersect in the $M-N-$ space as is shown in Figure $1 .^{5}$

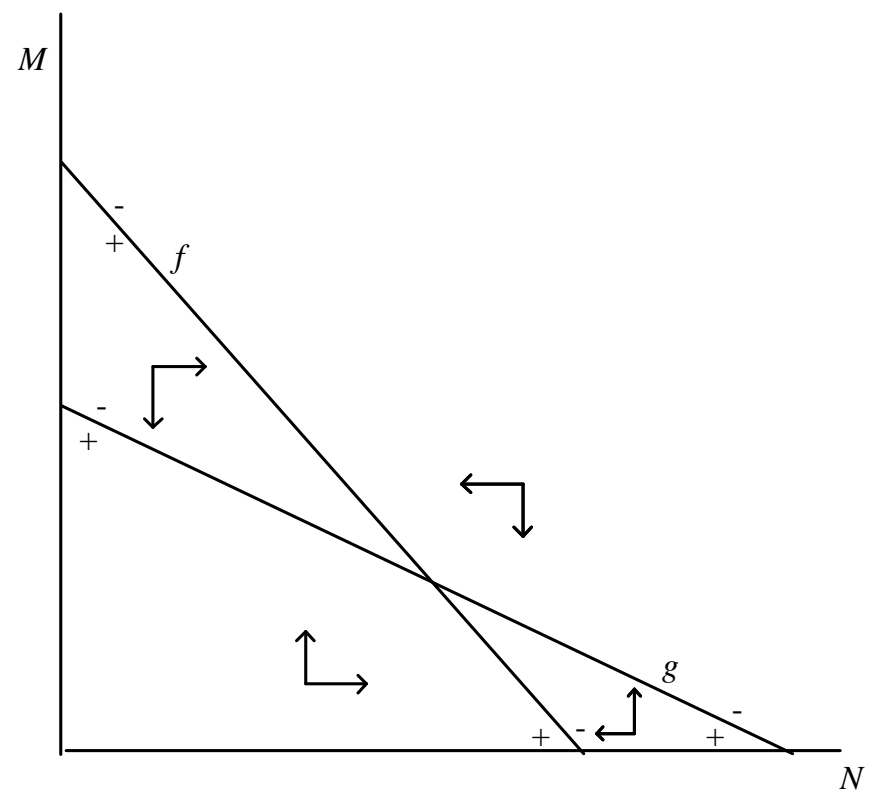

Figure 1: Mixed equilibrium

As Proposition 1 has shown, it might happen that only one type of firm, either national or multinational firms, is active in the market. In this case, $f$ and $g$ do not intersect. Figure 2 depicts the equilibrium with only multinational firms, since the $g$-curve lies to the right of the $f$-curve. In this case, $F_{f}(t)$ is so low (high) that all national firms exit the market, once FDI is liberalized. The equilibrium values for the number of firms, individual output levels and prices in a FDI regime with multinational firms only are:

$$
\begin{gathered}
M^{* *}=(\alpha-c) \sqrt{\frac{2}{\beta\left(F_{d}+F_{f}\right)}}-1 \\
x_{d}^{* *}=x_{f}^{* *}=\frac{\alpha-c}{\beta\left(M^{* *}+1\right)}=\sqrt{\frac{F_{d}+F_{f}}{2 \beta}},
\end{gathered}
$$

\footnotetext{
${ }^{5}$ Note that the slopes in all figures are linear only for ease of exposition. The positive Jacobian guarantees also that comparative statics yield reasonable results.
} 


$$
p_{d}^{* *}=p_{f}^{* *}=\frac{\alpha+c M^{* *}}{M^{* *}+1}=c+\sqrt{\frac{\beta\left(F_{d}+F_{f}\right)}{2}} .
$$

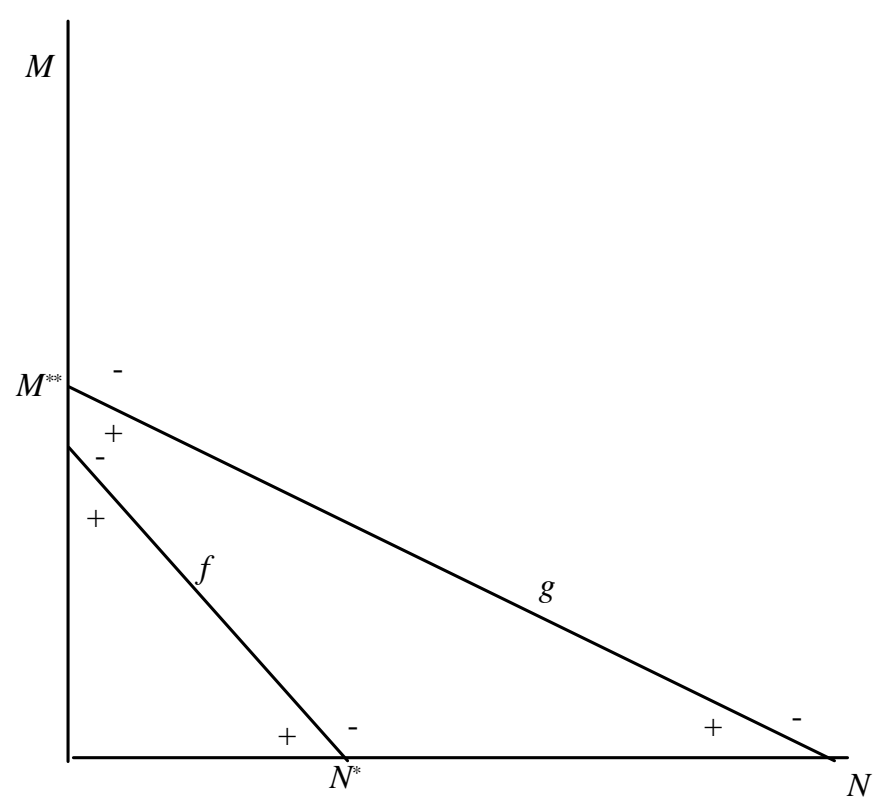

Figure 2: Equilibrium with multinational firms only

We can also determine the condition when an equilibrium with only multi national firms emerges. Once this occurs, firms are forced to invest abroad to remain active in both the domestic and the foreign market. It is clear from Figure 2 that this condition can be determined by setting $f\left(0, M^{* *}\right) \leq 0$. In this case, market entry is not profitable even for a single national firm. By using (12), we derive the following condition for an equilibrium with only multinational firms, which is consistent with Proposition 1:

$$
f\left(0, M^{* *}\right) \leq 0 \Leftrightarrow \beta F_{f} \leq t \sqrt{2 \beta F_{d}-t^{2}} .
$$

In summary, the lower the fixed costs to undertake FDI and/or the larger the trade costs, the greater the possibility that only multinational firms are active in the market. It is also interesting to note that the larger $F_{d}$, the greater the possibility for multinational firms to serve the markets alone. The intuition behind this result is that the larger the fixed costs to start the 
production process at home, the greater the size of the firms should be in order to avoid losses. The size of the multinational firms is larger than that of national firms because they do not carry trade costs.

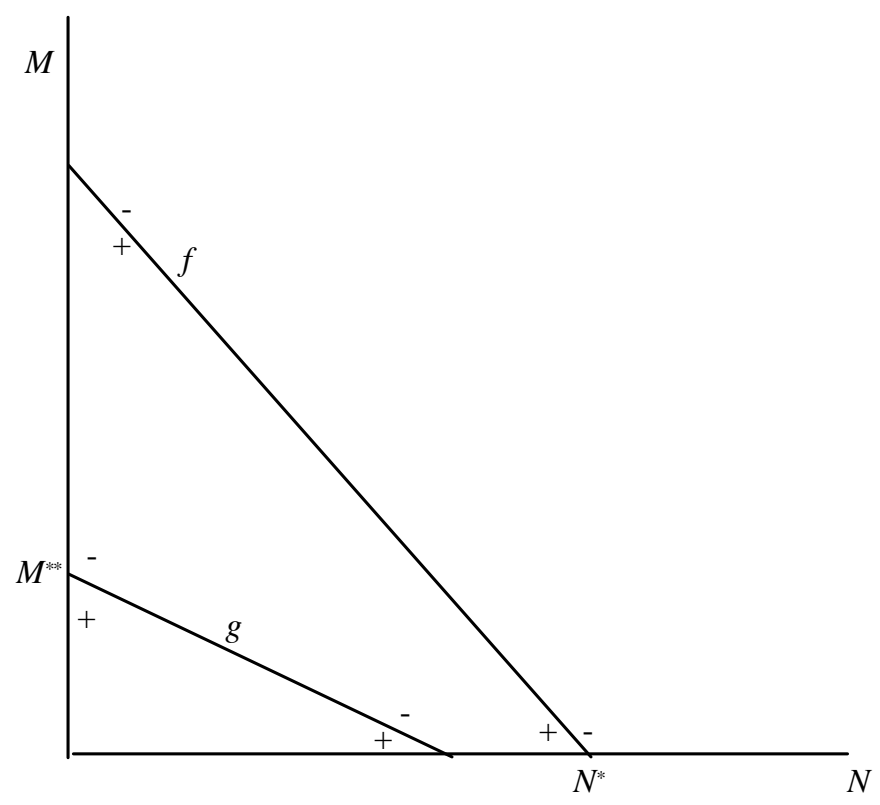

Figure 3: Equilibrium with national firms only

If $F_{f}(t)$ is sufficiently high (low), then multinational firms are not profitable. Figure 3 depicts this case, which occurs if $g\left(N^{*}, 0\right) \leq 0$. By using (13), we derive the following condition for an equilibrium with only national firms, which is also consistent with Proposition 1:

$$
g\left(N^{*}, 0\right) \leq 0 \Leftrightarrow \beta F_{f} \geq 2 t(\alpha-c-t) \sqrt{\frac{\beta F_{d}}{(\alpha-c)^{2}+(\alpha-c-t)^{2}}}+t^{2} .
$$

Namely, the greater the fixed costs to undertake FDI, and/or the lower the trade costs, the greater the possibility that only national firms are active in the market.

Having identified the conditions under which firms are active in the domestic and foreign markets, investigating the impact of FDI liberalization on market structure is straightforward. If FDI is liberalized and multinational firms are profitable, the market structure changes. Lemma 1 and Lemma 2 
summarize the results.

Lemma 1: In the mixed equilibrium, the total number of active firms under the FDI regime is lower than that under the intersectoral trade case.

Proof: The total number of active firms is given by $N^{e}+M^{e}$. The impact of FDI on market structure can be easily examined by using (4), (17), and (18). In fact, $M^{e}+N^{e}<N^{*}$ if, and only if,

$$
\left[(\alpha-c)^{2}+(\alpha-c-t)^{2}\right]\left(\beta F_{f}-t^{2}\right)^{2}<4(\alpha-c-t)^{2} t^{2} \beta F_{d}
$$

This expression is fulfilled if, and only if, the condition for the equilibrium with only national firms (25) is violated. Since this is the case, we can argue that allowing FDI leads to more concentration on the supply side if national firms survive.

The intuition of this result can be summarized as follows. We have shown that national and multinational firms sell the same amount in the domestic market (see (20)). Given the zero profit condition, the profits from exporting have to equal the profits of setting up a foreign subsidiary. If the total number of firms rose after liberalization, a national firm would necessarily earn less from exporting, since the foreign market is more crowded, and multinational firms have a marginal cost advantage. This implies that national firms would have to earn more at home, which is inconsistent with entry. Hence, in any coexistence outcome, FDI leads to exit.

Lemma 2: In the equilibrium with only multinational firms, the impact of a regime switch from intersectoral trade to FDI on the market structure depends upon parameter values:

$M^{* *}<N^{*}$, if

$$
\frac{F_{d}}{F_{d}+F_{f}}<\frac{(\alpha-c)^{2}+(\alpha-c-t)^{2}}{2(\alpha-c)^{2}}
$$

while $M^{* *}>N^{*}$, if 


$$
\frac{F_{d}}{F_{d}+F_{f}}>\frac{(\alpha-c)^{2}+(\alpha-c-t)^{2}}{2(\alpha-c)^{2}}
$$

Proof: The condition for the equilibrium with only multinational firms (24) can be re-arranged as follows:

$$
\frac{F_{d}}{F_{d}+F_{f}} \geq \frac{(\alpha-c)^{2}+\left(\alpha-c-t-t M^{* *}\right)^{2}}{2(\alpha-c)^{2}}
$$

Expression (29) is consistent with both (27) and (28).

Lemma 2 maintains that there is scope for market concentration even if only multinational firms are active in the market. In particular, the number of active firms under the FDI regime is lower, only if national firms are not active at the margin. However, we cannot rule out the possibility that $M^{* *}>N^{*}$. If $F_{f}$ is very small, the equilibrium number of multinational firms could be so large that a pro-competitive effect occurs.

The impact of FDI on market structure has an effect on the welfare of both the domestic and the foreign country, because equilibrium prices and quantities depend upon the equilibrium number of firms and the costs of production. Based on Lemma 1 and Lemma 2, we prove the following Proposition 2.

Proposition 2: In the mixed equilibrium, the welfare of the domestic country under the FDI regime is lower than that under the intersectoral trade case. In the equilibrium with only multinational firms, the welfare of the domestic country can either increase or decrease. The welfare of the foreign country rises in both cases.

Proof: Given the zero profit condition, the welfare analysis can be carried out by examining the impact of FDI on prices. If the foreign market is served via exports, prices are given by (6). If only multinational firms are active in the market, the domestic price and the foreign price coincide and are given by (23). If instead national and multinational firms coexist, prices 
are given by (19). By comparing (6), (19) and (23), it is evident that the domestic consumer is worse off if, and only if, the total number of active firms under the FDI regime is smaller than the number of national firms under the trade regime. If both national and multinational firms are active, the domestic consumer is worse off, because market concentration occurs (see Lemma 1). If only multinational firms are active, Lemma 2 claims that the impact on market structure and, therefore, on domestic welfare depends on parameter values. Hence, the welfare effects for the domestic country stated by Proposition 2 are proven.

Conversely, the representative consumer in the foreign country is always better off, if FDI is liberalized. In this case, two effects have to be considered: firstly, due to higher total fixed costs, the exit of firms can occur, bringing about a rise in foreign prices, which decreases foreign welfare; secondly, the foreign consumer benefits unambiguously from lower production costs, as foreign prices can be set at a lower level. The proof of the foreign country's welfare improvement can be given by contradiction. Suppose that $p_{f}$ given by (19) is larger than $p_{f}$ given by (6). Then, an increase in the foreign price occurs if, and only if,

$$
\beta F_{f}>2 t(\alpha-c-t) \sqrt{\frac{\beta F_{d}}{(\alpha-c)^{2}+(\alpha-c-t)^{2}}}+t^{2} .
$$

However, if this inequality were true, multinational firms would not be active and only national firms would serve the market (see condition (25)). Hence, if coexistence occurs, the foreign price under the FDI regime ought to be lower than that under the intersectoral trade case. This finding holds also for the equilibrium with only multinational firms. In fact, condition (30) tells us that $p_{f}$ is lower under coexistence, including the border case where $N^{e}=0$ and $M^{e}=M^{* *}$. If $F_{f}$ is smaller, then the number of multinational firms increases. In addition, if the market is served only by multinational firms, then no trade costs have to be carried by foreign consumers. Hence, the welfare of the foreign country is larger under the equilibrium with only multinational firms compared to the equilibrium with only national firms. 
To clarify the last argument, consider the equilibrium with only national firms as depicted in Figure 3. A decrease in $F_{f}$ implies a shift of the $g$-curve to the right. If $F_{f}$ is sufficiently smaller, coexistence of national and multinational firms would occur. We have shown that this leads to welfare gains for the foreign country, including the border case for which $N^{e}=0, M^{e}=M^{* *}$. Given this corner solution, a further decrease in $F_{f}$, by strengthening the profitability of FDI, leads to a larger number of active multinational firms and, as a result, to larger welfare gains.

Another interesting question is how small $F_{f}$ should be to ensure that the domestic country is not worse off. Since we have already proven that the domestic country is worse off in the case of coexistence, it is obvious that the domestic country can become better off only if merely multinational firms are active in the market, and if $p_{d}^{* *} \leq p_{d}^{*}$. Thus, the critical amount of plantspecific fixed costs can be computed by setting expression (21) larger than or equal to expression (4). The domestic country is therefore not worse off if, and only if,

$$
F_{f} \leq \psi F_{d}, \psi:=\frac{(\alpha-c)^{2}-(\alpha-c-t)^{2}}{(\alpha-c)^{2}+(\alpha-c-t)^{2}}
$$

Only if $F_{f}$ is small enough, does the domestic country gain from FDI, because the equilibrium number of multinational firms would be larger than the equilibrium number of national firms under the trade regime. However, it seems that $F_{f}$ should be really small for a pro-competitive effect to occur with FDI liberalization. In fact, consider a possible case where marginal costs are $10 \%(30 \%)$ of the reservation price and trade costs are $30 \%$ of the marginal costs. In this case, the critical parameter $\psi$ would be equal to 0.0339 (0.1368). In other words, the fixed costs to set up a plant abroad should be lower than $3.39 \%(13.68 \%)$ of the fixed costs to start the production process at home for the domestic consumer to be better off.

\section{FDI versus intraindustry trade}

The previous section has shown the effects on market structure and welfare of FDI liberalization compared to intersectoral trade, under the assumption 
that the headquarters of the oligopolistic industry were run only in the domestic country. In this section, we discuss how these results vary, when the headquarters of the oligopolistic industry are run in both countries.

If FDI is banned, the model is identical to that of Brander and Krugman (1983) used to study the welfare effects of intraindustry trade caused by the rivalry of oligopolistic firms under free entry. They show that trade with respect to autarky is mutually welfare improving, as firms move down their average costs curves. If FDI is liberalized, aggregate outputs are determined by $X_{d}=n x_{d}^{n}+m x_{d}^{m}+\tilde{n} x_{f}^{\tilde{n}}+\tilde{m} x_{f}^{\tilde{m}}$ and $X_{f}=n x_{d}^{f}+m x_{f}^{m}+\tilde{n} x_{d}^{\tilde{n}}+\tilde{m} x_{d}^{\tilde{m}}$, where $n(\tilde{n})$ and $m(\tilde{m})$ denote the number of national firms and the number of multinational firms having the headquarters in the domestic (foreign) country, respectively. By symmetry, the equilibrium number of national and multinational firms will coincide. Hence, we need to consider only one market. The profit of each national firm and each multinational firm is still given by (2) and (3), respectively. Since all types of firms are possibly present in the market, define $N=2 n$ and $M=2 m$. The solution of the standard profit maximization problems faced by the firms yields

$$
\begin{gathered}
p=\frac{\alpha+c N+0.5 t N+c M}{N+M+1}, \\
x_{d}^{n}=x_{d}^{m}=x_{f}^{m}=\frac{\alpha-c+0.5 t N}{\beta(N+M+1)}, x_{f}^{n}=\frac{\alpha-c-t-0.5 t N-t M}{\beta(N+M+1)} .
\end{gathered}
$$

Given the profit maximizing output and prices, profits (2) and (3) can be re-arranged as follows:

$$
\begin{gathered}
\phi(N, M):=\frac{(\alpha-c+0.5 t N)^{2}}{\beta(N+M+1)^{2}}+\frac{(\alpha-c-t-0.5 t N-t M)^{2}}{\beta(N+M+1)^{2}}-F_{d}=0 \\
\gamma(N, M):=\frac{2(\alpha-c+0.5 t N)^{2}}{\beta(N+M+1)^{2}}-F_{d}-F_{f}=0
\end{gathered}
$$

where $\phi$ denotes the zero profit condition for national firms, and $\gamma$ denotes the zero profit condition for multinational firms. $\phi$ and $\gamma$ would allow us to determine the equilibrium number of both national and multinational 
firms. However, the Jacobian determinant of (34) and (35) with respect to $N$ and $M$ is zero, which implies that (34) and (35) are linearly dependent and no equilibrium solution with positive $N$ and $M$ exists. ${ }^{6}$ Consequently, the equilibrium in a symmetric Cournot oligopoly with entry can only be a corner solution, which leads to the conclusion that either only multinational firms or only national firms are in the market.

Proposition 3: If the oligopolistic industry is located in both countries, firms are either all national or all multinational.

Proof: See appendix.

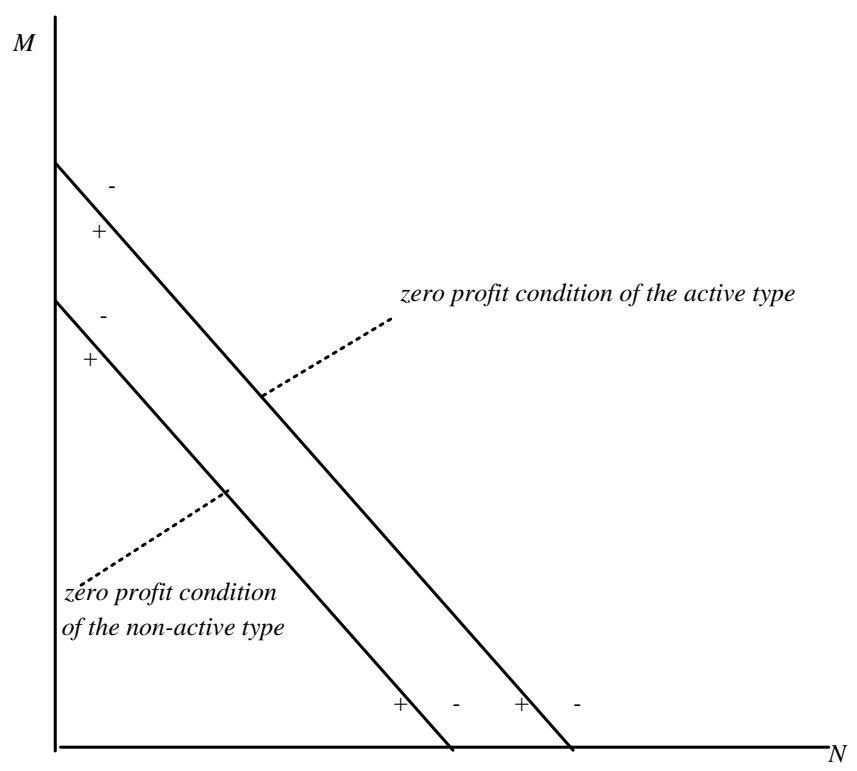

Figure 4: Equilibrium with one firm type only

In order to examine which type of firm is active in the market, it is useful to compare the implicit functions in the $M-N$ - space. The zero Jacobian implies that (34) and (35) could only intersect with identical slopes, which contradicts the assumption of intersection (see Figure 4). Since $\partial \phi / \partial N, \partial \phi / \partial M, \partial \gamma / \partial N, \partial \gamma / \partial M<0$, the points under (above) the $\phi-(\gamma-)$

${ }^{6}$ See appendix for a proof. 
curve represent positive (negative) profits for national (multinational) firms. Then, the zero profit condition of the active type will lie above the zero profit condition of the non-active type.

Since the pre-liberalization equilibrium point is represented by (8) with national firms making zero profits, FDI is profitable if, and only if, $\gamma(\tilde{N}, 0) \geq$ 0. $\gamma(\tilde{N}, 0) \geq 0$ implies that multinationals may enter without making losses and - as Proposition 3 has shown - would dominate the market. Once FDI is liberalized, the condition for the equilibrium with multinational firms only is given by:

$$
\gamma(\tilde{N}, 0)=\frac{2(\alpha-c+0.5 t \tilde{N})^{2}}{\beta(\tilde{N}+1)^{2}}-F_{d}-F_{f} \geq 0,
$$

which leads to (24), because, if the world is served by multinational firms only, it does not matter where their headquarters are located. Hence, if $\beta F_{f} \leq$ $t \sqrt{2 \beta F_{d}-t^{2}}$, national firms do not survive and the equilibrium number of multinational firms is given by (21), regardless of the initial location of the headquarters. $^{7}$

With regard to the impact on market structure, by inserting (21) into (36), and rearranging, we obtain

$$
M^{* *} \geq \frac{\alpha-c-0.5 t}{\alpha-c+0.5 t \tilde{N}} \tilde{N}
$$

Since $(\alpha-c-0.5 t) /(\alpha-c+0.5 t \tilde{N})<1$, industry concentration may also occur in the case of intra-FDI. But we cannot rule out the possibility of a pro-competitive effect, because the fixed costs to set up a plant abroad could be so small that the equilibrium number of firms rises.

However, and most importantly, (37) is very useful for the welfare analysis. In fact, (37) is consistent with the price equation (32) under the two alternative regimes if, and only if, $p\left(0, M^{* *}\right) \leq p(\tilde{N}, 0)$. This implies that the negative dumping effect, which occurs if homogeneous goods are traded internationally, plays a key role in the welfare analysis, regardless of the impact of a regime switch on market structure. Thus, we can conclude

\footnotetext{
${ }^{7}$ Conversely, if $\phi\left(0, M^{* *}\right) \geq 0$, the market would be served by national firms only.
} 
our analysis with the following proposition.

Proposition 4: Although the impact on the market structure of the intra-FDI regime compared to the intraindustry trade case depends upon parameter values, intra-FDI generates mutual welfare gains.

This is a remarkable result because it stresses the role of trade costs. Consider a firm switching from a national to a multinational firm because FDI has been liberalized. Then, a decline in the domestic price implies a decrease in the individual domestic output. In addition, the multinational firm has to carry the additional plant-specific fixed costs. Both these profit reducing effects are offset by vanishing trade costs to meet the zero profit condition.

\section{Concluding remarks}

This paper has examined the impact of FDI liberalization on market structure and welfare under the key assumptions that the equilibrium number of firms is derived by the zero profit condition and that trade and FDI are perfect substitutes. We have distinguished two different scenarios concerning the location of headquarters, under the hypothesis that FDI is either banned or liberalized. If headquarters are run in the domestic country only and FDI is banned, any trade regime is of the intersectoral type. If headquarters are run in both countries and FDI is banned, any trade regime is of the intraindustry type. Given these two different benchmarks, we studied the impact of liberalizing FDI on market structure and welfare by comparing the two FDI regimes with the two trade regimes.

We have shown that, if the headquarters are run in the domestic country only, the FDI regime compared to the intersectoral trade case leads to welfare losses for the domestic country, but to welfare gains for the foreign country, when national and multinational firms are both active. However, if only multinational firms emerge, the welfare of the foreign country improves, whereas the impact on the welfare of the domestic country depends upon 
parameter values. This ambiguity depends on the impact of FDI on market structure, which we have shown to be negative if both types of firms coexist, but depending on parameter values if only multinational firms are active. Conversely, if the headquarters of the oligopolistic industry are run in both countries, the FDI regime compared to the intraindustry trade case leads to mutual welfare gains, although the equilibrium number of multinational firms can be lower than that of national firms.

\section{Acknowledgements}

We are indebted to Jonathan Eaton, Winfried Ethier, Horst Herberg, James Markusen, Anthony Venables and two unknown referees for valuable comments and suggestions. This paper has been presented at conferences of the European Association for Research in Industrial Economics and of the German Economic Association (Verein für Socialpolitik), the workshop on multinational enterprises, economic development and policies of the Kiel Institute of World Economics, the workshop on international economics of Passau University, the departmental seminars of the Norwegian School of Economics and Business Administration in Bergen and the Center for Economic Studies of Munich University. We wish to thank the participants for very useful discussion. All errors are our responsibility.

\section{Appendix}

\section{Proof of uniqueness of the mixed equilibrium}

Uniqueness is proven if the Jacobian has an unambiguous sign for the equilibrium values of $N$ and $M$. Differentiation of the zero profit conditions yields

$$
\begin{gathered}
\frac{\partial f}{\partial N}=-\frac{2\left((\alpha-c)^{2}+(\alpha-c-(M+1) t)^{2}\right)}{\beta(N+M+1)^{3}}<0, \\
\frac{\partial f}{\partial M}=\frac{\partial g}{\partial N}=-\frac{2\left[(\alpha-c)^{2}+(\alpha-c+N t)(\alpha-c-(M+1) t)\right]}{\beta(N+M+1)^{3}}<0,
\end{gathered}
$$




$$
\frac{\partial g}{\partial M}=-\frac{2\left((\alpha-c)^{2}+(\alpha-c+N t)^{2}\right)}{\beta(N+M+1)^{3}}<0 .
$$

For the negative signs of all derivatives see also (20). The Jacobian is then

$$
|J|=\frac{\partial f}{\partial N} \frac{\partial g}{\partial M}-\frac{\partial f}{\partial M} \frac{\partial g}{\partial N}=\frac{4(\alpha-c)^{2} t^{2}}{\beta^{2}(N+M+1)^{4}}=\frac{\eta^{2}}{[2 \beta(\alpha-c) t]^{2}}>0 .
$$

Expression (A.4) shows that the sign of the Jacobian is unambiguously positive. Note that this property holds also for the corner solutions characterized by $f(0, M)=g(0, M)=0$ or $f(N, 0)=g(N, 0)=0$.

\section{Proof of Proposition 3}

Proposition 3 claims that the Jacobian of (34) and (35) is zero. Differentiation of (34) and (35) yields

$$
\begin{gathered}
\frac{\partial \phi}{\partial N}=-\frac{[(\alpha-c)+(\alpha-c-t)-t M]^{2}}{\beta(N+M+1)^{3}}<0 \\
\frac{\partial \phi}{\partial M}=\frac{\partial \gamma}{\partial N}=-\frac{2(\alpha-c+0.5 t N)[(\alpha-c)+(\alpha-c-t)-t M]}{\beta(N+M+1)^{3}}<0 \\
\frac{\partial \gamma}{\partial M}=-\frac{4(\alpha-c+0.5 t N)^{2}}{\beta(N+M+1)^{3}}<0
\end{gathered}
$$

By using (A.5), (A.6) and (A.7), we find that

$$
|J|=\frac{\partial \phi}{\partial N} \frac{\partial \gamma}{\partial M}-\frac{\partial \phi}{\partial M} \frac{\partial \gamma}{\partial N}=0
$$

\section{References}

Blonigen, B.A. (2001), In search of substitution between foreign production and exports, Journal of International Economics, 53: 81-104.

Brainard, S.L. (1993), 'A simple theory of multinational corporations and trade with a trade-off between proximity and concentration', NBER Working Paper, n. 4269. 
Brainard, S. L. (1997), 'An empirical assessment of the proximityconcentration trade-off between multinational sales and trade', American Economic Review, 87: 520-540.

Brander, J.A. (1981), 'Intra-industry trade in identical commodities', Journal of International Economics, 11: 1-14.

Brander, J.A., Krugman, P.R. (1983), 'A "reciprocal dumping" model of international trade', Journal of International Economics, 15: 313-323.

Dunning, J.H. (1977), 'Trade, location of economic activity and MNE: A search for an eclectic approach', in Ohlin, B., Hesselborn, P.O., Wijkman, P.M. (eds.), The International Allocation of Economic Activity, London, Macmillan.

Helpman, E. (1984), 'A simple theory of trade with multinational corporations', Journal of Political Economy, 92: 451-571.

Helpman, E., Krugman, P.R. (1985), Market Structure and Foreign Trade, MIT Press, Cambridge.

Horstmann, I.J., Markusen, J.R. (1992), 'Endogenous market structures in international trade (natura facit saltum)', Journal of International Economics, 32: 109-129.

Markusen, J.R. (1984), 'Multinationals, multi-plant economies, and the gains from trade', Journal of International Economics, 16: 205-226.

Markusen, J.R. (1998), 'Multinational firms, location and trade', World Economy, 21: 733-756.

Markusen, J.R., Maskus, K.E. (2001), 'Discriminating among alternative theories of the multinational enterprise', in: M. Blomstrom, L. Goldberg (eds.), Topics in Empirical International Economics, Chicago University Press, Chicago.

Markusen, J.R., Venables, A.J. (1998), 'Multinational firms and the new trade theory', Journal of International Economics, 46: 183-203. 
Markusen, J.R. and Venables, A.J. (2000), The theory of endowment, intraindustry, and multinational trade, Journal of International Economics, 52: 209-234.

United Nations (2001), World Investment Report 2000, New York.

Wong, K. (1995), International Trade in Goods and Factor Mobility, Cambridge, MIT Press. 


\section{Proof: $x_{f}^{n e}=0$ and $x_{f}^{m e}>0$ imply $F_{f}>F_{d}$ (not for publication)}

If national firms serve only the domestic market, output levels per firm are

$$
\begin{array}{r}
x_{d}^{n e}=x_{d}^{m e}=\frac{\alpha-c}{\beta\left(N^{e}+M^{e}+1\right)}, \\
x_{f}^{n e}=0, \\
x_{f}^{m e}=\frac{\alpha-c}{\beta\left(M^{e}+1\right)},
\end{array}
$$

leading to the following zero profit conditions:

$$
\Pi^{n e}=\frac{(\alpha-c)^{2}}{\beta\left(N^{e}+M^{e}+1\right)^{2}}-F_{d}=0
$$

and

$$
\Pi^{m e}=\frac{(\alpha-c)^{2}}{\beta\left(N^{e}+M^{e}+1\right)^{2}}+\frac{(\alpha-c)^{2}}{\beta\left(M^{e}+1\right)^{2}}-F_{d}-F_{f}=0 .
$$

(B.2) and (B.3) imply that

$$
M^{e}=\frac{\alpha-c}{\sqrt{\beta F_{f}}}-1
$$

and

$$
N^{e}=\frac{\alpha-c}{\sqrt{\beta}}\left(\frac{1}{\sqrt{F_{d}}}-\frac{1}{\sqrt{F_{f}}}\right) .
$$

Clearly, $N^{e}>0$ if, and only if, $F_{f}>F_{d}$, which contraddicts one of our assumptions. 